\title{
Projected Population Size and Age Structure for Canada and Provinces: With and Without International Migration
}

\author{
Shirley Loh \\ Demography Division \\ Statistics Canada \\ Ottawa, Ontario, Canada \\ shirley.loh@statcan.ca \\ M.V. George \\ Adjunct Professor \\ Departments of Global Health and Sociology \\ Emory University \\ Atlanta, Georgia, USA \\ Department of Sociology \\ University of Alberta \\ Edmonton, Alberta, Canada \\ Adjunct Research Associate \\ Center for Population Studies \\ University of Mississippi \\ University, Mississippi, USA
}

\section{Abstract}

This paper examines the effect of net international migration on prospective population growth and age structure in Canada for the next 50 years. It also examines the impact of international migration on provincial growth and distribution. The procedure used in this study is by comparing two projected population scenarios, one with international migration and the other without international migration, based on the latest 2005-based population projections. The analysis of the scenarios shows that the assumed level of international migration which is higher than the current level contributes to a continuous increase in population over the next 50 years, but has limited effect to prevent or offset the overall aging trend.

Key Words: population projections, immigration, emigration, zero international migration 
Shirley Loh and M. V. George

\section{Résumé}

Ce document examine l'effet de la migration internationale sur la croissance prospective de la population et la structure par âge au Canada pour les 50 prochaines années. Il examine aussi l'impact de la migration internationale sur la croissance et la distribution provinciales. La démarche utilisée dans cette étude est de comparer les deux scénarios de population projetée l'un avec migration internationale et l'autre sans migration internationale, selon les dernières projections de population de 2005. L'analyse des scénarios démontre que le niveau présumé de migration internationale, plus élevé que le niveau actuel, contribue à une croissance continuelle de la population au cours des 50 prochaines années, mais a peu d'effet quand à la prévention ou la tendance au vieillissement.

Mots clés: projections de population, immigration, émigration, migration internationale nulle

\section{Introduction}

Future population size and age structure of a country are determined by the past, present and future patterns, and levels of fertility, mortality and international migration (immigration and emigration). The fertility level in Canada has decreased steadily to below replacement level since 1972, and significant change in this component of growth is not expected in the near future. The mortality trend, in terms of life expectancy at birth, has been slightly upward over the years in Canada. However, it has been shown that the continuing slight increase in life expectancy at birth has limited effect on future population size (George, Loh and Verma, 1997).

With fertility much below the replacement level over several years and low natural increase (the difference between births and deaths) of population, the contribution of net international migration (the difference between immigration and emigration) on current and future growth of the population has increased substantially. Since 1993, the Canadian population has grown more from net migration than from natural increase (Statistics Canada, 2001a). In 2000-2001, net international migration represented as high as $70 \%$ of total population growth. In that year the level of net migration including net non-permanent residents was 232,700 , with the annual immigration level of 252,500 , total emigration level of 55,400, and net non-permanent residents of 35,600 (Statistics Canada, 2005a). Since then the contribution of net international migration has been around $64 \%$ to $69 \%$ of the total growth. In 2004-2005 the 
level of net international migration was 192,900 with an annual immigration level of 244,600, total emigration level of 45,600 and net non-permanent residents of -6000 . When natural increase falls further and becomes negative, net international migration would become the sole factor of growth. The impact of high net international migration could have an effect on the growth and distribution of the provinces and territories as well.

Given the overwhelming significance of international migration to Canada's population growth, this paper examines the role of net international migration on future population growth and age distribution. The analysis would also indicate the effect of international migration as a mechanism to postpone prospective population decline and to counteract the inevitable increase in population aging in Canada with the increase in the number and proportion of the elderly, which will accelerate with the baby boom cohorts reaching the age of 65 in around 2011. The focus of the paper is to answer the question: in the absence of migration, when and how great would be the decline in population size and how large would be the impact of migration on population aging? It also examines the impact of international migration on provincial growth and distribution ${ }^{2}$. It should be noted that migration has a direct and indirect effect on population growth and age pattern, the former from the net addition of migration to population and the latter from the reproductive effect of immigrants or their descendants, which is determined by the immigrants' ages and their fertility level.

The approach here is a simulation analysis using two comparable projection scenarios, and the period of analysis is 26 years from 2005 for the provinces and 51 years for Canada, which is consistent with the projection period in the 2005based population projections (Statistics Canada, 2005b) ${ }^{3}$. The impact of the level of net international migration is examined by comparing the effect of two medium-growth scenarios, one assuming that the immigration rate in 2004 would reach 7.0 per thousand population in 2010, remain constant until 2031, and the projected number in 2031 (about 280,000) would remain constant thereafter, while the other assuming no international migration. In the current projections, the immigration assumption is formulated in terms of rate which assumes that future immigration level will evolve in relation to population growth. In the short term, the proposed level assumed in the medium assumption corresponds roughly to the midpoint of the range in the number of immigrants planned for 2006 outlined in the most recent immigration plan by Citizenship and Immigration Canada. The effect of net international migration on the projected age structure is analyzed in terms of three broad age groups: 0 $14,15-64$ and 65+. In addition, the median age, potential support ratios, and dependency ratios derived from the projected Canadian populations with and without international migration are examined. 
Before examining the effects of international migration, we should note the distinction between "zero international migration" and "zero net international migration". The latter refers to a situation where the number of immigrants and emigrants is the same, while the former refers to a "closed population" in which there is no immigration or emigration, i.e., the population is not affected by international migration (for further explanations, see Bouvier, Poston and Zhai, 1997). Although several countries assume zero international migration for demographic analysis purposes, it actually exists only for the world as a whole. Canada being an immigrant country, the term zero migration is a misnomer in Canadian demographics. However, in order to isolate and examine the demographic effects of net international migration, we have considered two comparable population scenarios: one with migration, and the other without migration, i.e., with zero migration as a component (see Table 1 for further details).

\section{Projection Method and Assumptions}

The population projection model employed in this study is the regional cohort component method. The procedure starts with the base-year population distribution by age and sex. Age-and-sex specific survival ratios, age-specific fertility rates, immigration and emigration rates are applied to this distribution and generate projected numbers of births, deaths, immigrants and emigrants. Projected numbers are also derived for persons temporarily abroad, returning Canadians, non-permanent residents, and interprovincial net migration. These are then either added to or subtracted from the base-year population, depending upon the case, to obtain the projected population for the following year. In order to obtain comparable and consistent projections for Canada, the provinces and the territories, a "bottom up" approach is used for producing projections at the provincial and territorial level. Projections at the national level are then derived by aggregating the projections for the provinces and territories.

The projection with international migration used in this study corresponds to the medium-growth scenario (Scenario / Projection 3) generated in the 2005 base population projections (Statistics Canada, 2005b). The scenario / projection without international migration is the medium variant of the 2005 base projections in which the numbers of immigrants and emigrants of all types are assumed to be zero during the projection period. The time horizon of the projections for the provinces and territories is 26 years, 2005 to 2031 and for Canada covers 51 years, extending up to 2056. Component assumptions were developed up to 2031, but projections were extended to 2056 by keeping the fertility, mortality and migration assumptions constant at the levels for 2031 (see Table 1 for details of the component assumptions). The utilization of longer- 
Table 1. Summary of Component Assumptions: Medium Growth Scenario

\begin{tabular}{|c|c|c|}
\hline Component & $\begin{array}{l}\text { Projection with International } \\
\text { migration (Scenario } 3 \text { of } 2005 \text { base } \\
\text { projections) }\end{array}$ & $\begin{array}{l}\text { Projection without International } \\
\text { Migration (special scenario) }\end{array}$ \\
\hline Fertility & $\begin{array}{l}\text { A constant fertility of } 1.5 \text { children per } \\
\text { woman throughout the projection } \\
\text { period }\end{array}$ & $\begin{array}{l}\text { A constant fertility of } 1.5 \text { children per } \\
\text { woman throughout the projection } \\
\text { period }\end{array}$ \\
\hline Mortality & $\begin{array}{l}\text { Life expectancy would reach } 81.9 \\
\text { years for males and } 86.0 \text { years for } \\
\text { females in } 2031 \text { and remain constant } \\
\text { thereafter }\end{array}$ & $\begin{array}{l}\text { Life expectancy would reach } 81.9 \\
\text { years for males and } 86.0 \text { years for } \\
\text { females in } 2031 \text { and remain constant } \\
\text { thereafter }\end{array}$ \\
\hline Immigration & $\begin{array}{l}\text { The } 2004 \text { immigration rate would } \\
\text { reach } 7.0 \text { per thousand in } 2010 \text { and } \\
\text { remain constant until } 2031 \text {, and the } \\
\text { projected number in } 2031 \text { would } \\
\text { remain constant thereafter }\end{array}$ & Zero immigration after 2004 \\
\hline $\begin{array}{l}\text { Emigration: Returning } \\
\text { Emigrants; and Persons } \\
\text { Temporarily Abroad }\end{array}$ & $\begin{array}{l}\text { A constant emigration rate of } 1.5 \text { per } \\
\text { thousand throughout the projection } \\
\text { period; } 38 \% \text { of emigrants return each } \\
\text { year; a net annual figure of } 26,000 \\
\text { persons reside temporarily abroad } \\
\text { from } 2005 \text { to } 2006 \text {, which will be } \\
\text { reduced linearly to } 22,000 \text { in } 2011 \text { and } \\
\text { that will be kept constant thereafter }\end{array}$ & Zero emigration after 2004 \\
\hline Non-permanent Residents & $\begin{array}{l}\text { A constant stock of } 390,000 \text { persons } \\
\text { per year. A zero balance is assumed } \\
\text { between persons entering this } \\
\text { population and those leaving it }\end{array}$ & $\begin{array}{l}\text { A constant stock of } 390,000 \text { persons } \\
\text { per year. A zero balance is assumed } \\
\text { between persons entering this } \\
\text { population and those leaving it }\end{array}$ \\
\hline Interprovincial Migration & $\begin{array}{l}\text { A medium assumption that represents } \\
\text { the average of the "recent trends" and } \\
\text { "west coast" assumptions }\end{array}$ & $\begin{array}{l}\text { A medium assumption that represents } \\
\text { the average of the "recent trends" and } \\
\text { "west coast" assumptions }\end{array}$ \\
\hline
\end{tabular}

Source: Statistics Canada 2005, Population Projections for Canada, Provinces and Territories, 2005-2031,

Catalogue no. 91-520-XPE (Occasional). 
Shirley Loh and M. V. George

range projections enables us to assess the long-term growth and age structure implications of the assumed demographic trends.

A discussion on the rationale for the assumptions on each component is described in detail in the report, Population Projections for Canada, Provinces and Territories, 2005-2031 (Statistics Canada, 2005b). In providing the rationale of the high fertility assumption, it has been noted that the fertility of the growing proportions of immigrants coming from high fertility countries is higher than that of the rest of the Canadian population. A continuing increase in the percentage of immigrants from such countries is taken as a plausible factor for the high fertility assumption (Statistics Canada, 2005b, p. 18). However, separate assumptions have not been made in the fertility projections to take into account the fertility differences between immigrants and the Canadian-born population. The projection methodology assumes that after arriving in Canada the immigrants experience the same fertility and mortality conditions as the rest of the Canadians. This is considered plausible because high fertility levels tend to decline over time, and the impact on the projection results of assuming differential fertility assumptions will be negligible since newly arrived immigrants constitute less than $1 \%$ of the total population (George, Loh and Verma, 1997).

\section{Projections Results}

\section{National Total Population}

The comparison is made between two medium growth scenarios described above: one with international migration and the other without international migration. The population of Canada for the year 2005 was estimated at 32.3 million. This is the postcensal estimate of the population of Canada on July $1^{\text {st }}$, 2005, which is based on the 2001 Census, adjusted for net census undercoverage. With international migration, if the medium growth assumptions hold good as described in Table 1, the population of Canada will increase to around 39.0 million by 2031 (Table 2 and Figure 1). The population will continue to grow thereafter to reach about 42.5 million by 2056 .

Under the medium-growth scenario with migration, natural increase would reach the zero mark around the year 2030 (Figure 2). The number of deaths, which has been going up, is expected to continue increasing during the projection period as the baby-boom cohorts move into older ages. The number of births will continue to increase until 2020, but it will decrease for the next 14 years and then increase again around 2034. The cyclical pattern in births reflects the echo effects of the baby boom generation. 
Table 2

Population of Canada, With and Without International Migration for Selected Years: 1996 to 2056

\begin{tabular}{|c|c|c|c|}
\hline Year & $\begin{array}{c}\text { With } \\
\text { International Migration }\end{array}$ & $\begin{array}{c}\text { Without } \\
\text { International Migration }\end{array}$ & Difference \\
\hline & & (in millions) & \\
\hline 1996 & 29.6 & & \\
\hline 2001 & 31.0 & & \\
\hline 2005 & 32.3 & & \\
\hline 2006 & 32.5 & 32.4 & 0.1 \\
\hline 2011 & 33.9 & 32.8 & 1.1 \\
\hline 2016 & 35.3 & 33.0 & 2.3 \\
\hline 2021 & 36.6 & 33.2 & 3.4 \\
\hline 2026 & 37.9 & 33.1 & 4.8 \\
\hline 2031 & 39.0 & 32.9 & 6.1 \\
\hline 2036 & 40.0 & 32.4 & 7.6 \\
\hline 2041 & 40.8 & 31.7 & 9.1 \\
\hline 2046 & 41.4 & 30.8 & 10.6 \\
\hline 2051 & 42.0 & 29.8 & 12.2 \\
\hline 2056 & 42.5 & 28.8 & 13.7 \\
\hline
\end{tabular}

Source: 1996-2005: Statistics Canada, Annual Demographic Statistics, 2005, Catalogue no. 91-213-XIB; 2006-2056: Statistics Canada, Population Projections for Canada, Provinces and Territories, 2005-2031, Catalogue no. 91-520-XPE, and Statistics Canada, Demography Division. 
Shirley Loh and M. V. George

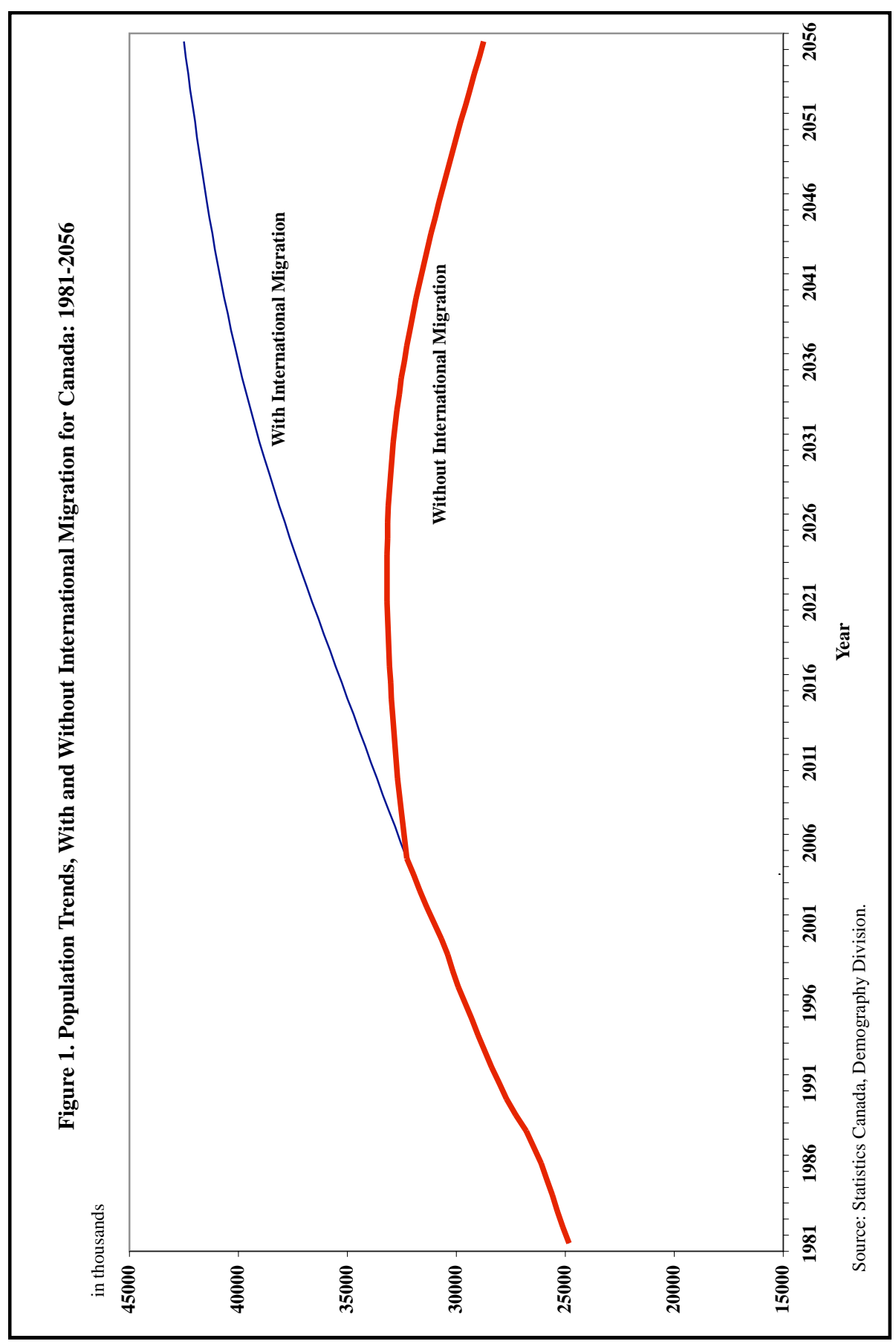

CSP 2007, 34.2: 103-127 
Projected Population Size and Age Structure for Canada and Provinces: With and Without International Migration

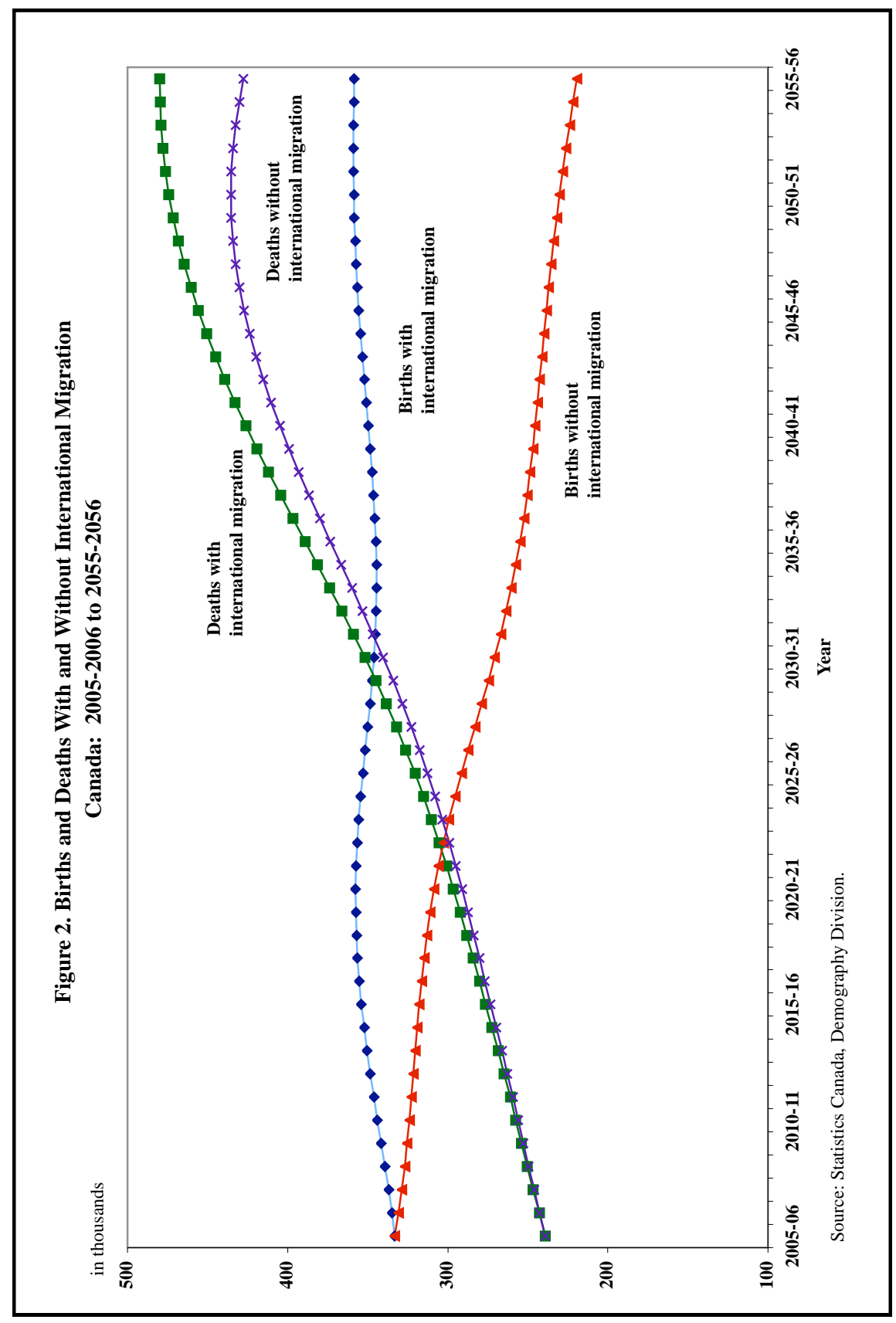

CSP 2007, 34.2: 103-127 
If no international migration is to occur under the medium growth scenario, and the growth is the result of natural increase only, the population of Canada would continue to grow to 33.2 million by 2023 (when deaths will exceed births), and fall to 28.8 million in 2056. The study on stationary population by George, Lachapelle and Romaniuc (2002) has shown that under the scenario with zero international migration and below replacement fertility level, the population, in the long run, would eventually lead to extinction. In the present context of low fertility below replacement level and possible negative natural increase by around 2023, when deaths will exceed births, immigration becomes the main factor of growth.

The annual difference in total population size between the two scenarios can be discussed in terms of direct effects, and indirect effects, i.e., cumulative net international migration, and cumulative natural increase, respectively. The difference in total population between the medium scenario and the scenario that assumes no international migration indicates the numerical contribution of net international migration to population growth, which amounts to over 6 million in 26 years between 2005 and 2031 and 14 million in 51 years by 2056 . The higher difference in the latter period could be attributed to different immigration assumptions for the two periods: an increasing immigration rate up to 2010 which would remain constant thereafter up to 2031; and a constant number of annual immigrants of around 280,000 which is the level reached in 2031, from 2032 to 2051 (see Table 1).

In addition to the direct impact of international migration, there are sizable indirect demographic effects on the receiving country due to immigration, since immigrants not only live in their country of destination, they also have children while living there (Bouvier, Poston and Zhai, 1997). The indirect effect of international migration in this comparison which can be measured as natural increase is less than 1 million when cumulated from 2005 to 2031 and to around 3 million for the period 2005 to 2056 .

The contribution of net international migration to the growth of Canada's population in terms of growth rate is evident in Table 3. The average annual rate of growth was around $0.9 \%$ between 1996 and 2001. If no migration occurs after 2005, the average annual rate of growth for the subsequent period of 2006 to 2011 will drop abruptly to $0.2 \%$. The population will experience negative growth between 2026 and 2031. Between 2051 and 2056, the annual growth rate will drop to $-0.7 \%$. 
Projected Population Size and Age Structure for Canada and Provinces:

With or Without International Migration

Table 3

Average Annual Rate of Population Change

Canada: 1996-2001 and 2051-2056

\begin{tabular}{ccc}
\hline Year & $\begin{array}{c}\text { With } \\
\text { International } \\
\text { Migration }\end{array}$ & $\begin{array}{c}\text { Without } \\
\text { International } \\
\text { Migration }\end{array}$ \\
\hline (in percent) & \\
$2001-2005$ & 0.9 & \\
$2005-2006$ & 1.0 & \\
$2006-2011$ & 0.9 & 0.3 \\
$2011-2016$ & 0.8 & 0.2 \\
$2016-2021$ & 0.8 & 0.2 \\
$2021-2026$ & 0.7 & 0.1 \\
$2026-2031$ & 0.7 & 0.0 \\
$2031-2036$ & 0.6 & -0.2 \\
$2036-2041$ & 0.5 & -0.3 \\
$2041-2046$ & 0.4 & -0.4 \\
$2046-2051$ & 0.3 & -0.6 \\
$2051-2056$ & 0.3 & -0.7 \\
& 0.2 & -0.7 \\
\hline
\end{tabular}

Source: 1996-2005: Statistics Canada, Annual Demographic Statistics, 2005,

Catalogue no. 91-213-XIB; 2006-2056: Statistics Canada, Population Projections for

Canada, Provinces and Territories, 2005-2031, Catalogue no. 91-520-XPE, and Statistics Canada, Demography Division.

According to the medium-growth scenario with the assumed international migration, the average annual rate of population growth will decrease from $0.9 \%$ between 1996 and 2001, to $0.6 \%$ between 2026 and 2031, then further fall to $0.2 \%$ between 2051 and 2056. Since the annual immigration rate remains constant in this projection, the decreasing annual rate of population growth is mainly attributable to the slowing and eventual negative natural increase. This in turn is predominantly due to a substantial increase in the number of deaths. 


\section{Total Population by Province ${ }^{4}$}

Unlike at the national level, the provincial analysis covers the actual projection period, 2005-2031 and not extended beyond. The geographical distribution of immigrants is quite uneven among the provinces, with Ontario, British Columbia, Quebec and Alberta being the major receiving provinces which together received around 96\% of the total immigrants $(252,500)$ in 2000-2001. Ontario which accounts for $38 \%$ of the Canadian population attracted nearly $59 \%$ of immigrants in 2000-2001. In the same year the second province that attracted the most immigrants was British Columbia which took in almost $16 \%$ of the total immigrants, followed by Quebec with 15\% and Alberta, 7\% (Statistics Canada, 2002). By 2004-2005 the total number of immigrants had fallen to 244,600 with some change in provincial ranking of immigrants received. Ontario continued to receive the largest number of immigrants with $53 \%$ of the Canada total followed by Quebec moving to the second rank with $18 \%$ of immigrants, British Columbia 17\%, and Alberta 7\% (Statistics Canada, 2005a).

How immigrants are distributed among the provinces and what is the impact of immigration on projected population growth? Figure 3 portrays the projected growth with and without international migration among the provinces during the projection period, 2005-2031. The growth of population with international migration includes the direct and indirect effects of immigrants. The indirect effect represents the natural increase among immigrants or the descendants of immigrants who arrived during the 26-year period. The analysis provides the decomposition of the direct and indirect effects of immigration by examining the growth with and without international migration. The description of the provincial distribution here is focused on the four major immigration destination provinces, and the analysis is limited to the first 26 years of the latest projections, up to 2031.

Ontario with a population of around 12.5 million in 2005 will grow to over 16 million by 2031 , if it continues to attract 127,000 to 155,000 immigrants annually between 2006 and 2031 (or around 103,000 to 129,000 net international migration). In the absence of international migration in the next 26 years, Ontario's population will increase to 12.8 million around 2031. Further, the numerical difference between the medium-growth projection with international migration and the projection that assumes no international migration will be around 3 million for Ontario by 2031 (Figure 3). 
Projected Population Size and Age Structure for Canada and Provinces: With and Without International Migration

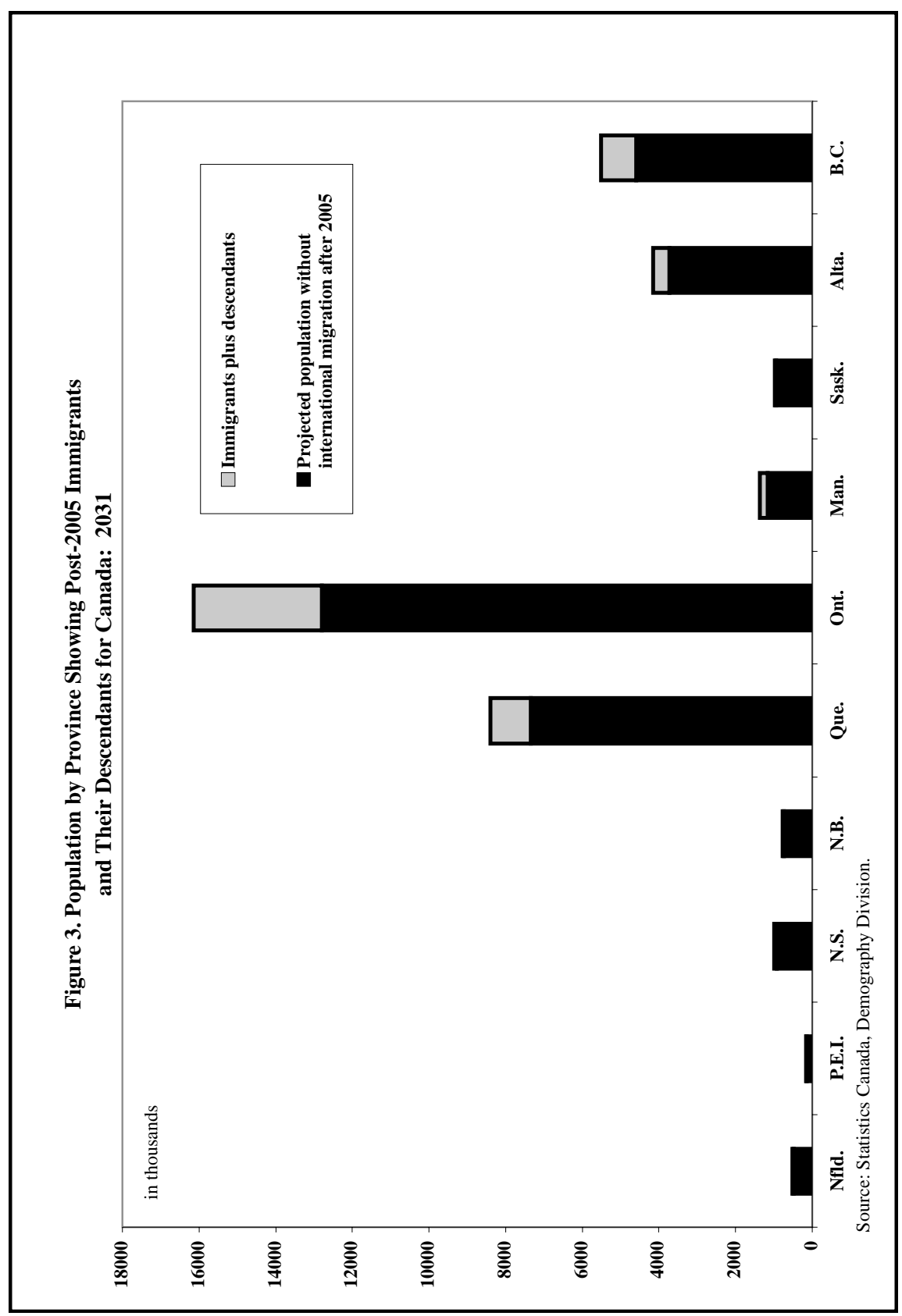

CSP 2007, 34.2: 103-127 
In the medium-growth scenario with international migration, it is assumed that around 44,000 immigrants will enter Quebec annually between 2006 and 2031or roughly 35,000 net international migration. Under this assumption, the population of Quebec will continue to increase to 8.4 million around 2031 from 7.6 million in 2005. In the absence of international migration in the next 26 years, Quebec's population will decline to 7.3 million by 2031. At the end of the projection period (2031), as a result of the combined direct and indirect effects of international migration, the difference in projected population between the scenarios with migration and without migration would amount to around 1 million.

Under the assumption that around 38,000 to 46,000 immigrants (or around 26,000 to 35,000 net international migration) enter British Columbia annually during the projection period (2006-2031), its population will increase from 4.3 million in 2005 to 5.5 million in 2031. If no international migration occurs after 2005, the population of British Columbia would be lower at 4.6 million in 2031. The difference in projected numbers between the two scenarios will be around 0.9 million.

Alberta's population is projected to grow from nearly 3.3 million in 2005 to 4.1 million in 2031 if Alberta receives between 17,000 to 20,000 immigrants annually in the next 26 years or between 10,000 and 13,000 net international migration. If no international migration occurs in Alberta, the population will be growing at a slow pace to 3.7 million by 2031 . The comparison between the projected populations under the medium-growth scenario with international migration and those under no international migration scenario shows that the contribution of international migration to population growth in Alberta could be around 428,000 over the next 26 years.

\section{Total Population by Age}

The age structure of immigrants is usually younger than that of the host population. For example, in 2000, persons aged 25-39 made up 43\% of the total immigrant population compared with $23 \%$ of the corresponding total population; therefore it is a common belief that immigration can offset the effects of population aging in the host country. However, the analyses of migration flows of recent decades in developed countries have provided scant evidence to support this belief (United Nations, 2000). The study of demographic consequences of the migration flows since the end of the Second World War in seven developed countries, namely Australia, Belgium, Canada, France, Germany, Italy and Sweden by Le Bras (1991) shows that the "rejuvenating" effect of migration on the host populations has been fairly modest. Immigration 
has lowered the average age of the population in these seven countries by 0.4 to 1.4 years. Similar conclusions were reached by other studies that analyzed the effects of the inflows of immigrants on the future age structure of a host population. Lesthaeghe, Page and Surkyn (1988) projected the age structure of twelve European countries with and without migration up to the year 2060. They conclude that the overall aging trend in these countries can be attenuated through immigration but it cannot be prevented.

As a result of a continuing sub-replacement fertility level since the early 1970 s and its assumed continuation during the projection period, Canada's population will undergo considerable aging in the $21^{\text {st }}$ century. This is reflected in the projected increase in the median age from 38.5 years in 2005 to 44.3 years in 2031 and further to 46.9 years in 2056, under the medium assumption on immigration and emigration (Table 4). In the absence of international migration, the median age would be 2.7 years older than that of the projected population with migration by 2031, and 4.2 years older by 2056 .

Another measure of aging, aging index confirms the continuing enormous aging of the Canadian population in the scenarios with international migration and without international migration (Table 4). In 2005, Canada's population can be described as old, with an aging index of 74.2 persons aged 65 and over to every 100 persons under 15 . With international migration, the aging index will increase to 160.5 and 200.5 by 2031 and 2056, respectively. Without international migration, the aging index will increase to 198.6 by 2031 and to 266.3 by 2056 . Thus, compared with the scenario without international migration will have 38 and 66 more persons aged 65 and over to every 100 persons under age 15 by 2031 and 2056, respectively. The reproductive effect of international migration on the receiving country helps to lower the aging index during the projection period but the aging trend cannot be prevented.

The age structure data on the medium-growth scenario with international migration (Table 5) show that by 2016 at the latest, Canada will have far more elderly (65 years and over) than younger (under age 15) people. Consequently, the proportions of the young and working-age groups would decline faster under the scenario with no international migration, a difference of 1.3 percentage points for the 0-14 age group and 4 percentage points for the 15-64 age group by 2056 , as compared with the scenario incorporating migration. On the contrary, the proportion aged 65 and older would increase at a much faster pace from $13.1 \%$ in 2005 to $32.5 \%$ in 2056 , under the scenario without migration. 
Shirley Loh and M. V. George

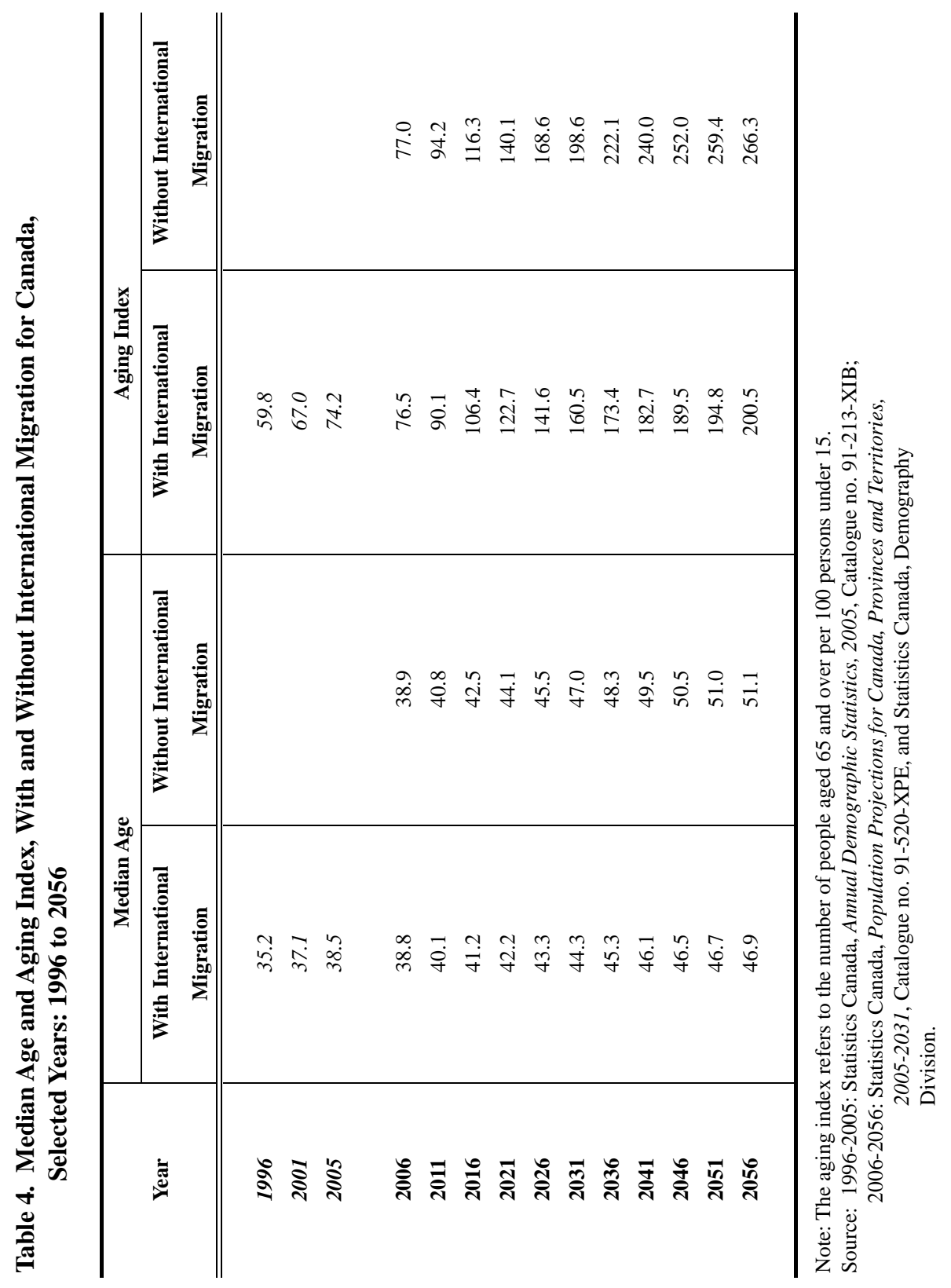


Projected Population Size and Age Structure for Canada and Provinces: With and Without International Migration

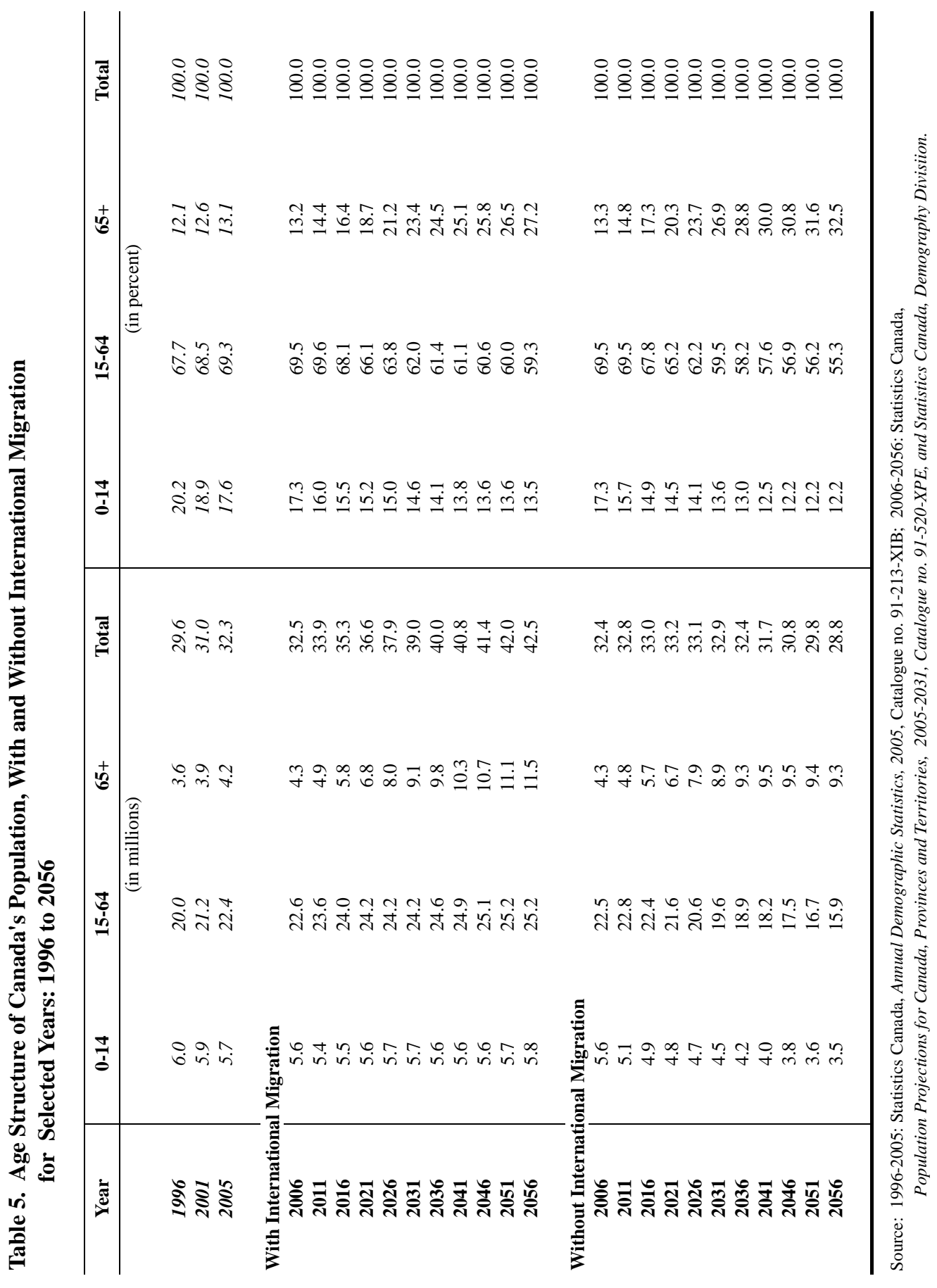


The comparison of the two scenarios also indicates that migration has had only a modest effect in rejuvenating the population of Canada. Even if the population is affected by a net gain in international migration of 183,000 to 221,000 annually over a 51-year period, 2005 to 2056 , the proportion of the elderly to the total population would be lowered only by 5.3 percentage points.

Further, the impact of continued aging of the population is readily apparent from the measure, potential support ratio, which is the number of working-age people per senior. Figure 4 shows that between 2005 and 2031, this ratio will decline from 5.3 working-age persons for each senior to about 2.6 in the scenario with migration and 2.2 in the scenario without migration. The ratio will decline further to around two working-age persons for each senior by 2056 whether the projections include international migration or exclude international migration.

In the latest population projections of Canada (Statistics Canada, 2005b), even in the high growth scenario (Scenario 6) assuming an increase in fertility to 1.7 children per woman by 2016, and an increase in immigration rate to 8.5 per thousand population by 2010 (i.e., an increase in annual immigrants from 239,000 in 2005 to 364,000 in 2056), the potential support ratio in 2031 is projected to be 2.7, about the same as that of the projection scenario with migration (Scenario 3) presented in this study, and by 2056, the ratio will only increase to 2.3 working-age persons for each senior, rather than 2.2. The limited effect of international migration on the future age structure of the Canadian population is also presented by George, Nault and Romaniuc (1991). A threefold increase in the annual number of immigrants from 140,000 to 500,000 during a 25-year projection period would not produce significant effect on the young and elderly population. The proportion of the age group 0-19 would increase from $22.4 \%$ to $23.6 \%$, while age group 65 and over would register a smaller decrease from $15.8 \%$ to $14.4 \%$. The substantial increase in immigration would have almost no impact on the $20-64$ age group, from $61.8 \%$ to $61.9 \%$.

Under the medium-growth scenario with international migration, the workingage group will account for $62 \%$ of the total population in 2031, down from $69 \%$ in 2005 . By 2056 , this proportion would have dropped to $59 \%$. In the absence of international migration, the working-age population will drop further to $60 \%$ and $55 \%$ by 2031 and 2056, respectively (Table 5).

The decline in the working-age population is also reflected in the demographic dependency ratio, the ratio of children (0-14) and elderly or seniors (65+) to the working-age population (15-64) (Table 6). Currently, for every 100 people of working age, there are 44 children and elderly people together (total dependency ratio) or 25 children and 19 elderly people. But the scenario with international migration shows that in 2031, the total dependency ratio would increase to 61 by 
Projected Population Size and Age Structure for Canada and Provinces: With and Without International Migration

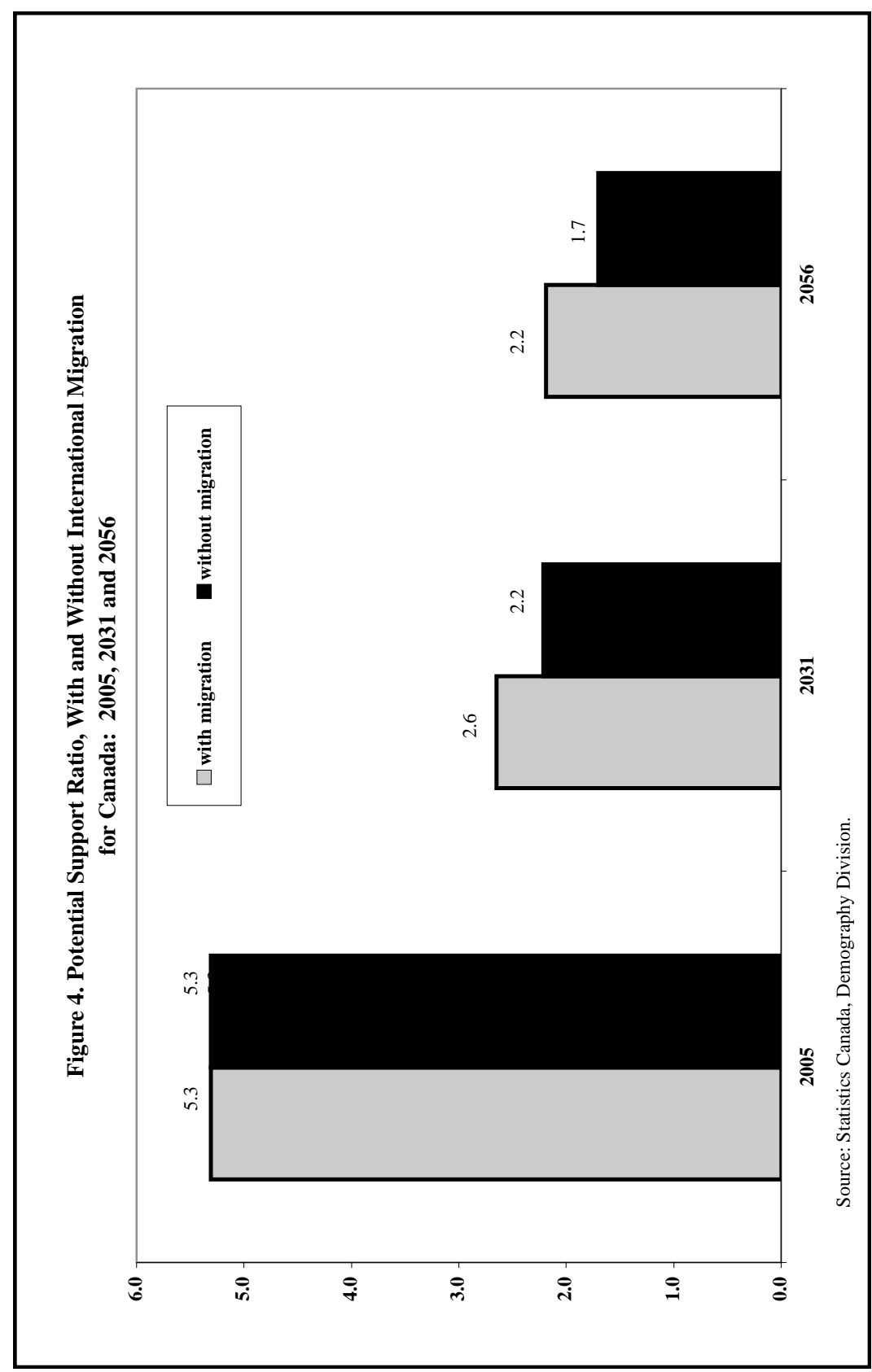

CSP 2007, 34.2: 103-127 
Shirley Loh and M. V. George

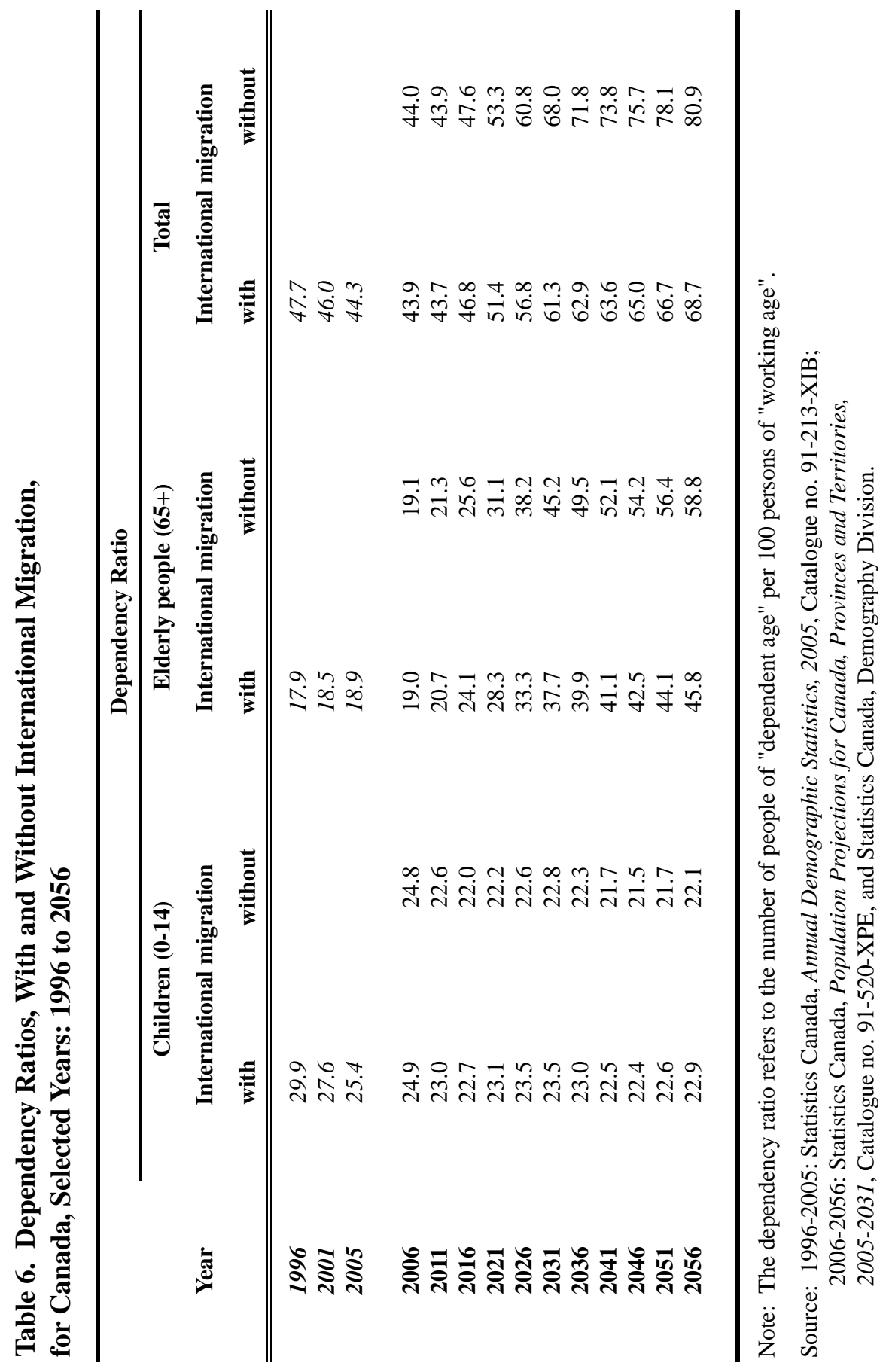

CSP 2007, 34.2: 103-127 
2031 and to 69 by 2056 . The dependency ratios will increase at a faster pace in the absence of international migration. The ratios would be 68 in 2031 and almost 81 by 2056. The rapid increase in the demographic dependency ratio in both scenarios after around 2011 is primarily due to the fact that the large babyboom cohorts would be reaching age 65 and over from this year on, and the decline in the working-age population (Table 5).

As the number and percentage of working-age population is decreasing faster in the scenario without international migration, the total dependency ratios and those for the elderly are higher in this than in the scenario with international migration. Both scenarios show that the child dependency ratios after 2011 would be lower than those for the elderly people, and that the difference between the two ratios would be greater in the scenario without international migration. The below replacement fertility in the past two decades and the decline in mortality have contributed to the lower child dependency ratios for children than for the elderly. The assumed increasing international migration would be accentuating the difference in the dependency ratios for the elderly and for the children in future years.

\section{Conclusion}

As revealed by the latest 2005 base population projections, the population of Canada, under the medium-growth scenario with international migration, would continue to grow during the coming fifty years to 39.0 million in 2031 and to 42.5 million by 2056 . In the absence of international migration, the population would increase to a peak of 33.2 million in around 2023 and then gradually start to fall to about 28.8 million in 2056. Thus, without international migration, Canada's population will cease to grow after 2023 when deaths will exceed births. During this period of about 18 years, the population will increase only by 912,000 to 33.2 million in 2023 . Thereafter, the population will decline to 32.9 million by 2031 , and to 28.8 million by 2056 . The comparison between the projected population under the medium-growth scenario with international migration and those under the no migration scenario shows that the contribution of net migration to population growth in Canada could be over 6 million over the next 26 years and about 14 million over the next 51 years (Statistics Canada 2005b).

Due to the continuing subreplacement level of fertility and with no indication that fertility will increase to a level close to the replacement level, international migration could play an instrumental role in offsetting population decline. In the absence of international migration, Canada's population will experience population decline after 2023 due to negative natural increase. With an inflow 
of roughly 183,000 to 221,000 net migration annually between 2005 and 2056 , population decline would not happen within the projection period.

Among the provinces, the contribution of net international migration to the provincial population growth is proportional to the net number of immigrants entering the province. Since more than $50 \%$ of the total immigrants in Canada settle in Ontario (53\% in 2005), the comparison of the scenarios with and without net international migration shows that the difference in its projected total population will be around 3 million by 2031, which is the largest among all the provinces.

Given the fact that age structure of immigrants is often younger than that of the host population, international migration seems to be a viable option in the short to medium term to reduce the decline in the working-age population. The projections presented show that with the presence of international migration, the working-age population in Canada will continue to grow during the projection period, with a size of 25.2 million in 2056 which is still larger than that in 2005 (22.4 million). In the absence of international migration, the projected workingage population will grow slower and will start to decline around 2016. By 2056, the size of the working-age population would be 15.9 million, 6.5 million less than that in 2005 .

As a result of the persistent below replacement fertility level and increased longevity, there will be profound changes in the age structure of Canada's population with an enormous increase in the number and proportion of the elderly. The scenarios presented show that international migration cannot prevent or offset the overall aging trend. A study done by George, Nault and Romaniuc (1991) comes up with similar conclusions that immigration effects are evenly spread over all age groups. Thus, it has little effect on age distribution. The study also shows that the initial age distribution would have the greatest impact on future age distribution. The future age distribution of the Canadian population will bear the mark of the post-war baby boom for many decades. A brief analysis of immigration on future population growth as a part of a broader study on impact of immigration in the receiving countries has come up with a similar conclusion that immigration assumptions (presented in the study) have a rather small impact on the age structure (Basavarajappa, Beaujot and Samuel, 1993).

Concern about an aging society is also often related to the changing ratio of the working-age population to the elderly population (potential support ratio). Net international migration of 183,000 to 221,000 per year will only help to raise the potential support ratio modestly, about 0.4 persons of working-age per elderly in 2031 and 0.5 in 2056. In sum, the analysis of the results of the two prospective 
Projected Population Size and Age Structure for Canada and Provinces:

With or Without International Migration

population scenarios, one with and the other without international migration, shows that even the increased assumed level of net international migration, which is higher than the current level, will not be able to reverse the population aging trend in Canada at least in the next 50 years.

\section{Acknowledgements:}

The authors wish to thank Alain Bélanger of Statistics Canada for providing the special projection scenario, and Ravi Verma, also of Statistics Canada for his helpful comments, and Daniel Larrivée of Health Canada and Julie Dussault of Statistics Canada for the French translation of the abstract. Support from Pamela White, Margaret Michalowski and André Cyr of Statistics Canada is gratefully acknowledged. Finally, we thank the two anonymous reviewers for their valuable comments and suggestions in an earlier version of this paper. The views expressed herein are those of the authors and do not necessarily reflect those of Statistics Canada.

\section{End Notes:}

1. This is a revised version of a paper presented at the annual meeting of the Canadian Population Society, Quebec City, 2001. It is extensively revised based on the updated Statistics Canada population projections for Canada, provinces and territories, 2005-2031.

2. The three territories are not included in the regional analysis due to the small number of immigrants destined to settle there. For example, in 2004-2005, the territories received a total of 147 immigrants out of the total annual number of 244,600 arrived in Canada.

3. These are the latest population projections for Canada, provinces/territories produced by Statistics Canada (for details, refer to Statistics Canada, 2005b).

4. At the provincial level, it is primarily internal migration that has the largest impact on future provincial population growth and distribution. The impact of this component is controlled in this study as are fertility and mortality components (see Table 1). 
Shirley Loh and M. V. George

\section{References}

Basavarajappa, K.G., R. P. Beaujot and T.J. Samuel. 1993. Impact of Migration in the Receiving Countries, Canada (ed. L.A. Kosinski). International Organization for Migration, Geneva.

Bouvier, L.F., D.L. Poston, Jr. and N.B. Zhai. 1997. "Population Growth Impacts of Zero Net International Migration". International Migration Review, Vol. 31 (2): 294-311.

George, M.V., R. Lachepelle and A. Romaniuc. 2002. "Stationary Population as a Vision for the Future: An Exercise in Normative Projection". Revised paper prepared for the annual meeting of the Canadian Population Society, May 30-June 1, 2002, Toronto, Ontario.

George, M. V., S. Loh and R. B. P. Verma. 1997. "The Impact of Varying the Component Assumptions on Projected Total Population and Age Structure in Canada". Canadian Studies in Population, Vol. 24 (1): 67-86.

George, M. V., F. Nault and A. Romaniuc. 1991. "Effects of Fertility and International Migration on Changing Age Composition In Canada". Statistics Journal of the United Nations Economic Commission for Europe, Vol. 8 (1): 13-24.

Le Bras, H. 1991. "Demographic Impact of Post-war Migration in Selected OECD Countries". In Migration. The Demographic Aspects. Paris: Organization for Economic Co-operation and Development, pp. 15-26.

Lesthaeghe, R., H. Page and J. Surkyn. 1988. “Are Immigrants Substitutes for Births?” IPD Working Paper 1988-3. Brussels: Interuniversity Programme in Demography.

Statistics Canada. 2001a. Annual Demographic Statistics, 2000. Catalogue No. 91-213-XPB. Ottawa.

Statistics Canada.2001b. Population Projections for Canada, Provinces and Territories, 2000-2026. Catalogue No. 91-520 (Occasional). Ottawa.

Statistics Canada. 2002. Annual Demographic Statistics, 2001. Catalogue No. 91-213-XPB. Ottawa. 
Projected Population Size and Age Structure for Canada and Provinces: With or Without International Migration

Statistics Canada. 2005a. Annual Demographic Statistics, 2005. Catalogue No. 91-213-XIB. Ottawa.

Statistics Canada. 2005b. Population Projections for Canada, Provinces and Territories, 2005-2031. Catalogue No. 91-520-XPE (Occasional). Ottawa.

United Nations. 2000. Replacement Migration: Is it a Solution to Declining and Ageing Populations? Population Division, New York. 